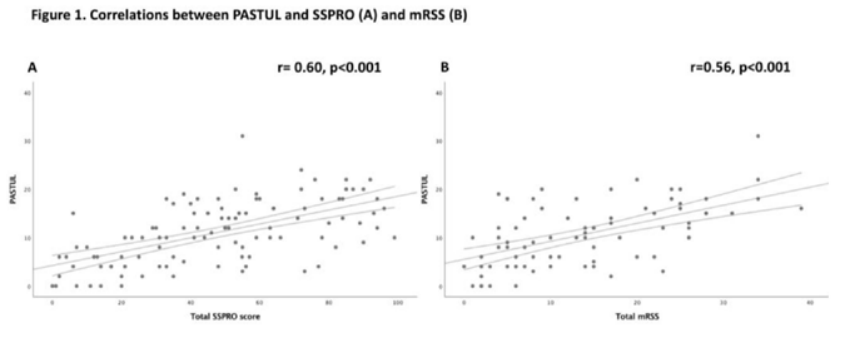

DOI: 10.1136/annrheumdis-2021-eular.75

\section{AB0403 ORBITAL MYOSITIS: AN UNCOMMON OPHTHALMIC PRESENTATION IN RHEUMATIC DISEASES - CASE SERIES AND SYSTEMIC REVIEW OF CASE REPORTS}

P. S. Wong ${ }^{1}$, B. G. T. Coumbe ${ }^{1}$, P. Mangat ${ }^{1}$, H. Beynon ${ }^{1}$, R. Stratton ${ }^{1} .{ }^{1}$ Royal Free Hospital and University College Medical School, Centre for Rheumatology and Connective Tissue Diseases, London, United Kingdom

Background: Ophthalmic conditions are common manifestations in patients with rheumatic diseases (RDs), orbital myositis (OM) remain rare. Only 1 case each for scleroderma and undifferentiated connective tissue disease (UCTD) reported. Objectives: Report frequency of Rheumatic Diseases with OM (RDs-OM), diagnosis and treatments.

Methods: Patients database were obtained from trust electronic record and literature review of case reports were performed.

Results: 4 out of 7 patients in our clinic with RDs-OM. Both Scleroderma-myositis (SCM) patients were positive for anti-PM/SCL antibody. All received glucocorticosteroid (GCS) and Mycophenolate as steroid-sparing or rescue therapy with good tolerance and outcome. One idiopathic OM has residual muscle paresis.

Table 1. Case series of patients with Orbital Myositis

\begin{tabular}{lccc}
\hline & $\begin{array}{c}\text { Idiopathic } \\
\text { OM } \\
(\mathbf{n}=3)\end{array}$ & $\begin{array}{c}\text { Rheumatology } \\
\text { Diseases } \\
(\mathbf{n}=4)\end{array}$ & p-value \\
\hline Age (years) & $48(27-72)$ & $42.75(21-60)$ & $\mathrm{P}=0.8571$ \\
$\begin{array}{l}\text { Gender - Female (Male) } \\
\text { Median Period Of Follow Up (months) }\end{array}$ & $24.60(7-37)$ & $47.25(1-120)$ & \\
Underlying RD & - & 1 & \\
I.UCTD & - & 2 & \\
II.Overlap Scleromyositis & - & 1 & \\
III.Behcet's Disease & 1 & 1 & \\
Biopsy & 1 & 1 & \\
I.Pathological significant & 1 & 2 & \\
II.Normal & & & \\
III.Not done & & &
\end{tabular}

Total 93 cases with RDs-OM reviewed and the characteristic of patients represented in Figure 1.

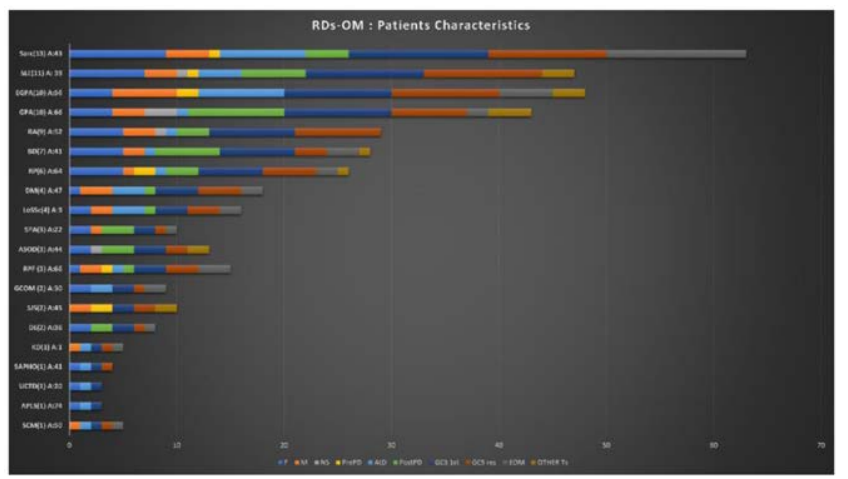

Figure 1. Characteristics of orbital myositis in patients with rheumatic diseases. F: female, M:male, NS: not-specified, PrePD: onset before RD, AtD: onset with RD,PostPD: onset after RD, GCS $1^{\text {st. }}$ Glucocorticoid as first line treatment, GCS res: Glucocorticoid responder, BxEOM: biopsy of extra-ocular muscle, OtherTs: Other Biopsy A: Median age at diagnosis, Sarc: sarcoidosis, SLE: Lupus, EGPA: Eosinophilic Granulomatous Polyangitis, GPA: Granulomatous Polyangitis, RA: rheumaoid Arthritis, BD: Behcet;s Disease, RP: Relapsing Polychondritis, DM: Dermatomyositis, LoSSC: Localized Sclerderma, SPA: Spondyloarthropathy, ASOD: Adult Onset Still's Disease, RPF: Retroperitoneal Fibrosis, GCOM: Giant Cell OM, SJS: Sjogren Syndrome, DL: Discoid Lupus, KD: Kawasaki Disease, SAPHO: Synovitis, acne, pustulosis, hyperostosis, and osteitis, APLS: Antiphospholipid Syndrome.
OM although is rare but can present in most RDs. Our review showed OM commonest in patients with RA, GPA, EGPA and sarcoidosis. Only 1 each for SCM, APLS, UCTD, SAPHO and Kawasaki Disease.

Most RDs-OM patients are female. $89.2 \%$ OM diagnosed concurrently with primary RD diagnosis. Majority RA, BD and GPA developed OM along the course of RDs (83\%-90\%).

Except for routine RDs screening, thyroid eye disease, infections, malignancy (eg. Iymphoma) and myasthenia gravis, atypical infective screenings include mycobacterium, fungal, Borrelia and spirochetes were excluded. Histopathological diagnosis is important diagnostic tool for IgG4 disease, neoplasm, sarcoidosis and vasculitis. $59 \%$ patients underwent tissue biopsy, $71 \%$ of these were sampled from EOM, some from involved organs. Orbital MRI or CT were the commonest diagnostic imaging, 5 reported had Ocular ultrasound as single or complementary imaging and 1 had PET-CT for exclusion of othe diagnosis.

Only $40 \%$ GPA and $20 \%$ of EGPA patients were positive for ANCA either c-ANCA p-ANCA and MPO which is similar in other literatures.

$97.8 \%(n=91)$ patients received GCS with $79 \%$ of these patients reported improvement or resolution of ocular symptom with or without steroid-sparing agents. Immunosuppressants used are those not foreign among rheumatologists while biologics prescribed for refractory cases were Rituximab(2), Infliximab(4), Adalimumab(2) and Tocilizumab(1). Orbital decompression and orbital radiation were other measures. 13 patients had residual EOM paresis.

Conclusion: 1.RDs-OM is increasing recognized.

2.Most $\mathrm{OM}$ in RA, BD and GPA occurs along its primary RDs.

$3.40 \%$ GPA and $20 \%$ of EGPA patients were ANCA positive.

4.GCS remain the primary treatment, three quarter patients responded.

REFERENCES:

[1] Murray PI. The eye and inflammatory rheumatic diseases. Best Practice \& Research Clinical Rheumatology. 2016.

Disclosure of Interests: None declared

DOI: 10.1136/annrheumdis-2021-eular.122

\section{AB0404 EXTENDED MYOSITIS PANEL AND THE CLINICAL ASSOCIATION IN PATIENT WITH SUSPECTED INFLAMMATORY DISEASE, A RETROSPECTIVE STUDY}

S. Al Nokhatha ${ }^{1}$, E. Alfares ${ }^{2}$, N. Conlon ${ }^{2}$, R. Conway ${ }^{1} .{ }^{1}$ St James's Hospital, Rheumatology, Dublin, Ireland; ${ }^{2}$ St James's Hospital, Immunology, Dublin, Ireland

Background: The idiopathic inflammatory myopathies (IIMs) are a heterogeneous group of conditions characterized by proximal muscle weakness. Autoantibodies are identified in more than $80 \%$ of patients with polymyositis (PM) or dermatomyositis (DM). Some are also found in other connective tissue diseases (CTD), while others are more specific to IIM. Thus, they are classified into two categories named myositis associated antibodies (MAA) and myositis specific antibodies (MSA). MSA have been reported as being $90 \%$ specific for IIM while MAA are found in up to $50 \%$ of myositis patients.

Objectives: The aim of the study was to evaluate the myositis antibody prevalence and to assess the associations of these antibodies with clinical manifestations, final diagnosis, medication received and outcomes.

Methods: A retrospective chart review study was conducted at St. James's Hospital from 2015-2020. All positive myositis panels were obtained. The MAA evalu ated were PMScl (100/75), U1snRNP, Ku and Ro52, while MSA were Mi2a, Mi2b, TIF1, MDA5, NXP2, SAE1, Jo-1, SRP, PL-7, PL-12, EJ and OJ.

Results: We identified 52 patients who were positive for one or more MSA MAAs. The mean age was 58.9 years, the majority were female $(65.3 \%)$ The most prevalent MAA was anti-Ro52 (29/52) followed by anti-PMScl 100/75 (7/52), anti-Ku and anti-U1RNP were seen in (3/52) each. The prevalence of MSA were (4/52) for anti-PL12 and (3/52) for anti-SAE1 followed by (2/52) for each of anti-Mi2b, anti-NXP2, anti-Jo, anti-SRP, anti-PL7, anti-EJ and anti-OJ while only (1/52) for anti-MDA5. The most common observed clinical phenotypes in our cohort were arthralgia (20/52), ILD (18/52) and cutaneous manifestations (15/52). Less than a quarter of the studied population had arthritis $(8 / 52)$, myositis $(7 / 52)$, raynauds $(7 / 52)$ and malignancy $(4 / 52)$. Various diagnosis were allocated for these patients, while only eight cases were diagnosed with dermatomyositis. Medication received and the final outcome for those with strong positive MSA were summarized in table1.

Conclusion: IIM was the final diagnosis in only $15 \%$ of positive myositis panels and the presence of antisynthetase antibodies didn't necessarily indicate the presence of antisynthetase syndrome thus signifying low specificity in our cohort.

\section{REFERENCES:}

[1] Ghirardello A, Borella E, Beggio M, Franceschini F, Fredi M, Doria A Myositis autoantibodies and clinical phenotypes. Auto Immun Highlights. 2014;5(3):69-75. Published 2014 Aug 23. 


\begin{tabular}{|c|c|c|c|c|c|c|c|c|c|c|}
\hline IIM & MSA & ILD & Arthritis & Arthralgia & Myositis & Raynauds & Cutanous & Malignancy & Final diagnosis & Treatment Outcome \\
\hline & NXP2 & & & & + & & + & & $\begin{array}{l}\text { Dermatomyositis } \\
\text { Myasthenia gravis }\end{array}$ & $\begin{array}{l}\text { Prednisolone + IVIG Remission/stable } \\
+ \text { Azathioprine + } \\
\text { pyridostigmine }\end{array}$ \\
\hline & MDA5 & & & + & & & + & & Amyopathic dermatomyositis & Prednisolone + MTX Remission/stable \\
\hline & SAE1 & & & & + & & + & & Dermatomyositis & Prednisolone + MTX Remission/stable \\
\hline ILD & PL12 & + & & & & & & & IPF & No medication Remission/stable \\
\hline \multirow[t]{4}{*}{ Ro52 } & PL12 & + & & & & & & & IPF & Prednisolone Died \\
\hline & $\begin{array}{l}\text { SAE1/ } \\
\text { OJ }\end{array}$ & + & & & & & & & IPF & No medication Lost follow-up \\
\hline & EJ & + & & & & & & & IPF & No medication Remission/stable \\
\hline & PL12 & + & & & & & & & $\begin{array}{l}\text { Interstitial pneumonia with autoimmune } \\
\text { feature (IPAF) }\end{array}$ & Under evaluation Remission/stable \\
\hline \multirow[t]{4}{*}{ Ro52 } & PL7 & + & + & + & & + & + & & Anti-synthetase syndrome & $\begin{array}{l}\text { Prednisolone }+ \\
\text { cyclophosphamide Remission/stable } \\
\text { then azathioprine }\end{array}$ \\
\hline & PL7 & + & & & + & & & & Anti-synthetase syndrome & Prednisolone + Remission/stable \\
\hline & & & & & & & & & & Rituximab \\
\hline & $\mathrm{JO}-1$ & + & & & & + & & & Anti-synthetase syndrome & No medication Remission/stable \\
\hline Ro52 & JO-1 & + & & & & & & & Anti-synthetase syndrome & $\begin{array}{l}\text { Prednisolone + MMF Remission/stable } \\
\text { then rituximab }\end{array}$ \\
\hline \multirow[t]{3}{*}{ CTD } & SAE1/ & + & & & & & & + & $\begin{array}{l}\text { Progressive pulmonary fibrosis (post COVID, } \\
\text { ARDS and recurrent aspiration) }\end{array}$ & $\begin{array}{l}\text { Antibiotics + } \\
\text { supportive care Remission/stable }\end{array}$ \\
\hline & SRP & & & & & & & & Esophageal Ca T1N2M0 s/p esophagectomy & \\
\hline & SRP & & & & & + & + & & Limited cutaneous scleroderma & Nifedipine Remission/stable \\
\hline Ro52 & EJ & & & + & & & & & Sjogren & HCQ Remission/stable \\
\hline Others & OJ & & + & + & + & & + & & MCTD & Prednisolone+ Remission/stable \\
\hline \multirow{3}{*}{$\begin{array}{l}\text { U1snRNP/ } \\
\text { Ro52 }\end{array}$} & & & & & & & & & Autoimmune hepatitis & Azathioprine+HCQ \\
\hline & & & & & & & & & & \\
\hline & NXP2 & & & + & & & & & Polymyalgia rheumatica & Prednisolone Remission/stable \\
\hline \multirow[t]{3}{*}{ ku } & $\mathrm{Mi} 2 \mathrm{~b}$ & & & + & & & & & large vessel vasculitis & $\begin{array}{l}\text { Prednisolone+ Remission/stable } \\
\text { Tocilizumab }\end{array}$ \\
\hline & PL12 & & + & + & & & + & & PsA & MTX Remission/stable \\
\hline & $\mathrm{Mi} 2 \mathrm{~b}$ & & & & & & & & PBC & $\begin{array}{l}\text { Ursodeoxycholic acid Remission/ } \\
\text { stable }\end{array}$ \\
\hline
\end{tabular}

Disclosure of Interests: None declared

DOI: 10.1136/annrheumdis-2021-eular.184

\section{AB0405 1 FIBROBLAST GROWTH FACTOR-23 IS ASSOCIATED WITH HIGH-DENSITY LIPOPROTEIN IN SYSTEMIC SCLEROSIS PATIENTS}

A. Alvarez de Cienfuegos ${ }^{1}$, L. Cantero-Nieto ${ }^{2}$, J. A. García-Gómez ${ }^{3}$, R. Ríos Fernández ${ }^{4}$, J. Martin Ibanez ${ }^{5}$, M. A. González-Gay ${ }^{6}$, N. Ortego ${ }^{4} .{ }^{1}$ Hospital Vega-Baja, Department of Rheumatology, Alicante, Spain; ${ }^{2}$ Hospital Santa Ana, Department of Emergency, Granada, Spain; ${ }^{3}$ Hospital General de Elche, Infectious Diseases Unit, Alicante, Spain; ${ }^{4}$ Hospital Universitario San Cecilio, Systemic Autoimmune Diseases Unit, Granada, Spain; ${ }^{5} I P B L N-C S I C$, Institute of Parasitology and Biomedicine López-Neyra, Granada, Spain; ${ }^{6}$ University of Cantabria, School of Medicine, Santander, Spain

Background: Systemic sclerosis (SSc) is characterized by calcification, vasculopathy, and endothelial wall damage, all of which can increase the risk for atherosclerosis and cardiovascular disease. Mechanisms by which atherosclerosis is promoted in connective tissue diseases remain unknown, but is believed to be secondary to chronic inflammation, altered lipid profiles and function, autoantibodies, and endothelial dysfunction. Fibroblast growth factor-23 (FGF23) is a circulating regulator of phosphate and vitamin D metabolism and has been implicated as a putative pathogenic factor in cardiovascular disease. FGF23 could exert hormonal control on fat mass and glucose metabolism, since it shares structural similarities with the other FGF subfamily members (FGF15/19 and FGF21) that are involved in carbohydrate and lipid metabolism.

Objectives: The objectives of this study were: to compare serum FGF23 levels between SSc patients and healthy controls and to investigate possible associations between FGF23 and serum lipid profile in SSc patients.

Methods: This cross-sectional study was performed in San Cecilio Hospital, Granada (Spain) from November 2017 to May 2019. Sixty-two women with SSc and 62 age and sex matched healthy controls were enrolled in this study. All patients included in this study had normal serum creatinine $(\mathrm{Cr})$ levels and met the 2013 American College of Rheumatology/European League Against Rheumatism (ACR/EULAR) criteria for SSc. Total cholesterol and triglyceride levels were determined by fully enzymatic techniques. High-density lipoprotein (HDL) was determined after precipitation of apolipoprotein B (apoB)-containing lipoproteins with magnesium sulfate and dextran sulfate. Low-density lipoprotein (LDL) was calculated using the Friedewald formula. Serum FGF23 was analyzed using ELISA.
Results: A total of 62 female patients were included in our study, with a mean (SD) age of $53 \pm 10$ years. The majority were Caucasian (90.5\%). The mean disease duration was $8.8 \pm 6.9$ years. Forty-four $(70.9 \%)$ patients had a limited form of the disease and $18(29.1 \%)$ had a diffuse form.

There was no significant differences in FGF23 levels between the patients and controls $(78.2 \pm 60.5$ vs. $80.3 \pm 56.3 \mathrm{pg} / \mathrm{mL}, p=0.662)$, but we found a statistically significant inverse relationship between FGF23 and HDL-c measurements $(r=-0.27 ; p=0.03)$ in women with SSc. In addition, in the linear regression model, higher FGF23 concentrations were associated with lower HDL-c $[\beta=-1.4595 \%$ $\mathrm{Cl}(-2.81,-0.08) ; \mathrm{p}<0.05]$.

Conclusion: We report an association between circulating FGF23 and HDL-C in SSc female patients, representing a novel pathway linking high FGF23 to an increased cardiovascular risk.

REFERENCES:

[1] Ho M, Veale D, Eastmond C, et al. Macrovascular disease and systemic sclerosis. Ann Rheum Dis. 2000; 59(1):39-43.

[2] McMahon M, Grossman J, FitzGerald J, et al. Proinflammatory high-density lipoprotein as a biomarker for atherosclerosis in patients with systemic lupus erythematosus and rheumatoid arthritis. Arthritis Rheum. 2006; 54(8):2541-9.

[3] O'Neill SG, Giles I, Lambrianides A, et al. Antibodies to apolipoprotein A-I, high-density lipoprotein, and C-reactive protein are associated with disease activity in patients with systemic lupus erythematosus. Arthritis Rheum. 2010; 62(3):845-54.

[4] Mirza MA, Alsio J, Hammarstedt A, et al. Circulating fibroblast growth factor-23 is associated with fat mass and dyslipidemia in two independent cohorts of elderly individuals. Arterioscler Thromb Vasc Biol. 2011; 31:219-227.

Disclosure of Interests: None declared

DOI: 10.1136/annrheumdis-2021-eular.302

\section{AB0406 ASSOCIATION OF ENDOTHELIN-1 WITH PULSE WAVE} VELOCITY IN SYSTEMIC SCLEROSIS PATIENTS

A. Alvarez de Cienfuegos ${ }^{1}$, L. Cantero-Nieto ${ }^{2}$, J. A. García-Gómez ${ }^{3}$, J. L. Callejas-Rubio ${ }^{4}$, J. Martin Ibanez ${ }^{5}$, N. Ortego ${ }^{4} .{ }^{1}$ Hospital Vega-Baja, Department of Rheumatology, Alicante, Spain; ${ }^{2}$ Hospital Santa Ana, Department of Emergency, Granada, Spain; ${ }^{3}$ Hospital General de Elche, Infectious Diseases Unit, Alicante, Spain; ${ }^{4}$ Hospital Universitario San Cecilio, Systemic Autoimmune Diseases Unit, Granada, Spain; ${ }^{5}$ IPBLN-CSIC, Institute of Parasitology and Biomedicine López-Neyra, Granada, Spain

Background: Systemic sclerosis (SSc) is a multisystemic disease featured by vascular and immunological disorders along with an excessive accumulation of the components of the connective tissue that cause cutaneous sclerosis and 